\title{
Clothing and meaning making: a multimodal approach to women's abayas
}

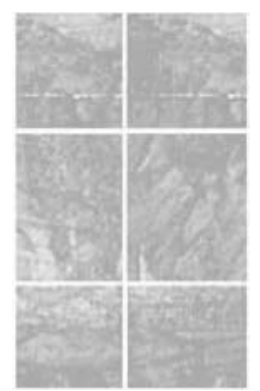

GWEN BOUVIER

Maynooth University, Ireland

\begin{abstract}
A B S TRACT
This article takes a multimodal discourse approach to women's fashion in the Middle East. It places the Islamic abaya in the UAE in the context of the wider literature on fashion and identity, exploring the way in which clothing features and forms can prescribe ideas, values and attitudes, and framing this discussion within newer ideas on globalization. As Roland Barthes argued, it is not so much personal choice or diversity in fashion that is of interest, but the kinds of values and expected behaviours that they imply. The abaya, on the one hand, represents a more newly arrived idea of traditional, local and religious identity, linking to some extent to an imagined sense of a monolithic notion of Islamic clothing. But, on the other hand, this is itself reformulated locally through international representations, ideas and values, and integrated with newer ideas of taste.
\end{abstract}

\section{KEYWORDS}

abaya $\bullet$ clothing semiotics $\bullet$ discourse $\bullet$ fashion $\bullet$ globalization $\bullet$ identity $\bullet$ Islamic fashion $\bullet$ Middle East $\bullet$ multimodality $\bullet$ semiotics

\section{INTRODUCTION}

Roland Barthes (1983: 33) argued that what is of interest in regard to fashion is not the diversity of clothing items, as it is dealt with in most literature on fashion history, nor the way clothing points to manners of personal expression, but the relativity of the values that they signify. It is not so important why and when black became a colour of mourning, but rather the kinds of ideas, values and social relations that this helps to infuse into this social practice, and in this sense 'presents a standardized picture of expected collective behaviour' (p. 13). 
This article is highly influenced by these ideas and also by Barthes' thoughts on how a semiotics of clothing might be developed - that different features, shapes, forms, fabrics, etc. can become aligned with certain kinds of meanings and identities. While, on the one hand, clothing may be something we choose to wear, that is, the act of dressing, for Barthes (2005), we also choose from a set of available choices, or dress. We are able to communicate things about ourselves through those semiotic resources already available to us, which in many ways are highly regulated and have certain meanings built into them. They guide both production and reception, and therefore shape social interaction (Kress and Selander, 2012). In this article, I use these ideas, exploring a social semiotic, or multimodal discourse approach to clothing, to look at the case of women's clothing in the United Arab Emirates (UAE).

The UAE has experienced rapid transformation since the discovery of oil in the 1960s: from a nomadic Bedouin society comprised of seven independent Emirates to a united country, building a sense of unified identity, that has experienced rapid modernization and population growth with immigrant workers now forming the majority of the population. There are high levels of wealth amongst the local Emirate population as oil money was widely distributed with a humanitarian and modernizing aim. Emiratis typically enjoy high-level consumer products and merchandise, drive top-level cars and buy expensive designer furniture.

One notable feature of these changes that should not be underestimated has been new possibilities for women to enter education and participate in the work force. Women were seen by the government as playing an important part in modernization. It was thought that women, formerly having a highly domestic role supporting men, needed to be included in order to culturally embed these changes. But women are also part of an 'Emiratization' policy where the aim is to gradually replace international workers in key skills and leadership positions. Given the relatively small population, women must be included. While the changes mark a quite incredible achievement, there has been resistance from men and a remaining lack of the sense that women are able to take leadership roles (Carvalho Pinto, 2012). Care has been put into presenting women's professional work, not as self-interest or ambition but through a more traditional discourse of giving to, and nurturing, the wider community.

Young women now in their 20s are the first to go through the national university system and are the first to have grown up in a society where there is a majority ex-pat population. They tend to have the economic means to access high-level consumer products and have a keen awareness of global styles, fashions and ideas. These younger women mostly wear a single long black garment called an abaya in public settings with a headscarf called a shayla (see Figure 1). This is promoted as a kind of national dress for women as part of nation building and is often described by the women themselves as a marker of tradition, of national culture, and allowing them to mark out an identity in contrast to the large immigrant population. It is also one way that Islamic identity can be signi- 


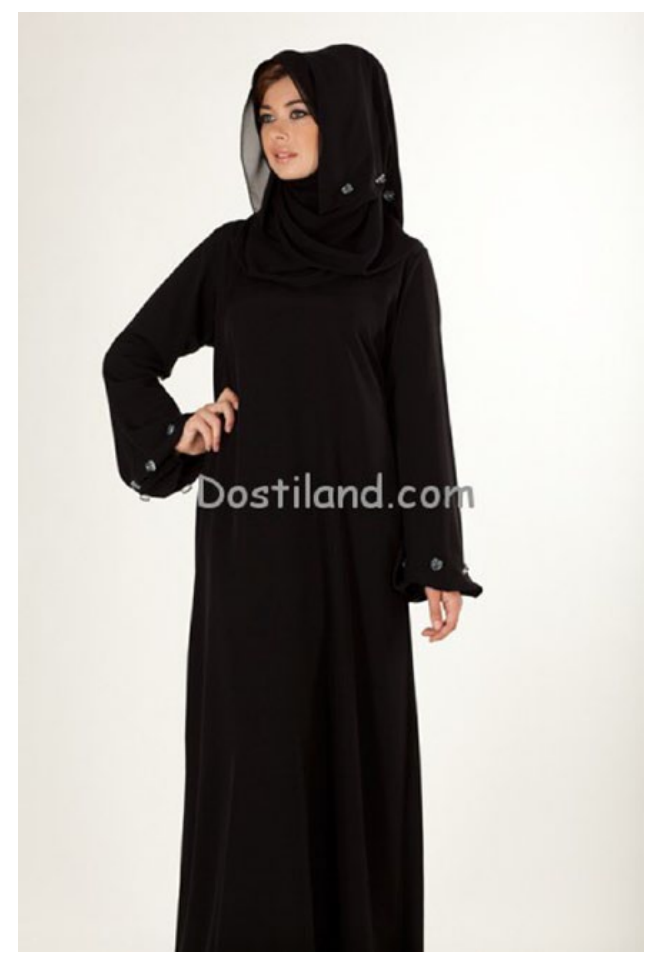

Figure 1. simple abaya.

https://stylehitz.com/wp-content/uploads/20I I/09/La-Reine-Abaya-Collection-www_She9_ blogspot_com-2.jpg

https://stylehitz.com/simple-abaya-for-girls/

fied, through covering. The abaya itself is a more recent arrival to the UAE. Its exact history has not been charted, although a number of authors point to its emergence in popularity in Saudi Arabia in the 1930s (Ambah, 2007) and its origin in Turkey and Syria (al-Muktar, 2011) before this. Photographs of Emirate women prior to the discovery of oil show a mixture of clothing, comprising different sections of skirts, tops, etc., often loose and of varying colours, with some women wearing the khimar (Figure 2), which comprises a single garment falling widely and loosely from the head, sometimes worn with jilbab trousers.

The abaya itself comes in many forms, with newer more modern fabrics becoming available and with versions incorporating international fashion elements, some being created by international designers and displayed on catwalks. And while some abayas cover completely, they are also worn in ways that do not do this, but rather signify the culture of covering, and can be combined with a range of other accessories. Young women also wear the abaya differently according to the requirements of social contexts. It is clear from my own interviews and from other studies on the role of women in the UAE (Bristol-Rhys, 2010) that they experience complex and clashing social pressures, with notions of modernization and the 


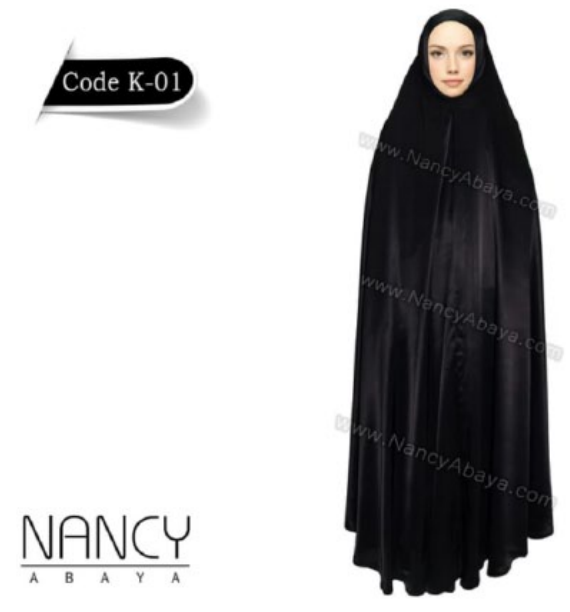

Figure 2. Full length khimar.

http://www.nancyabaya.com/khimar.html

encouragement to play a role in nation building sitting alongside those of family and religion, all with very specific ideas of how they should interact in public and with men.

In this article, I explore how we can usefully examine this process using social semiotics to draw out the meanings built into different kinds of features, forms and ways of wearing the abaya. This is placed specifically in more recent literature on globalization. While the abaya itself is used as a marker of local, ethnic and religious identity, how this is done must be understood through the flow of international discourses about style, identity, Islam and Westernization. Aiello and Pauwels (2014) note that we must understand much more about the way that globalization is not simply a matter of difference being suppressed, of the rise of sameness. Rather, the flow of ideas, values and images around the planet, across societies, regionally and internationally, take varying and specific ideological forms. Identity is something that is continually remade and re-imagined for different motivated purposes, and this will be done through transforming these globally available resources. In the context of the abaya, local identity is achieved through transformation of much that is global. This includes the appropriation of semiotic meanings of textures, fabrics and colours. It is not just that global fashions are combined or localized, but rather that these become transformed and can reformulate how the local is then understood.

The observations made in this article relate to reflections made by scholars of Islamic clothing (Tarlo, 2010) that while Western media, and also more conservative Muslim groups, tend to represent a rather monolithic idea of Islamic women's clothing, it is marked internationally by an incredible diversity and change, and by the expression of a wide range of ideas, values and alignments. 
This article carries out a social semiotic analysis of the abaya, which is supported by interviews with 50 female students. I first present some of the key ideas developed in the scholarly literature on fashion and clothing. This raises some important issues and concepts regarding how societies and individuals use clothing. I then consider how this can be placed with the newer globalization literature before carrying out the analysis of the abaya.

\section{CLOTHING AND MEANING MAKING}

One theme that runs through the scholarly literature on fashion is the idea of clothing as communication (Wilson, 1985). But this idea of communication is still only loosely defined and is treated often, as Barthes (2005) notes, as a sense of the communication of personal traits or taste, perhaps of social status and beauty. But he does not tend to dig deeper into features, forms, colours and textures.

At the heart of more critical scholarly work on fashion that has taken place since the publications of Barthes lies a tension between the mass produced nature of fashion, its power to categorize people and control them, and the way that it is used on a more personal level by individuals. Some scholars have usefully drawn on the ideas of Foucault to think about fashion as one form of social control (Miller, 2011). Foucault argued that societies organize themselves through processes of categorization and surveillance. These constitute a kind of disciplinary framework in regard to what is normal, abnormal, acceptable and unacceptable. He uses the concept of 'gaze' whereby we look at others and ourselves. This is how the body enters discourse, becoming part of social life, a tool of communication, and becomes inscribed with the forms of power policed by the disciplinary framework. And it becomes part of the way we experience ourselves and our body (Crane and Bovone, 2006). Fashion becomes one way that the body is shaped, presented and controlled in terms of these norms, not overtly, but related to social validation. For example, in some societies, age and appearance are very much scrutinized. The mass media discuss what older pop stars such as Madonna can and cannot do, and wear, how much of her body we should see and how she should move it.

Some feminist writers have seen fashion as a form of social control of women through its gendering and sexualization roles (Crane, 2000). Fashion distorts the natural body form through high heels, corsets and so on, and by objectifying styles that reduce women to objects of a sexualizing gaze (Twigg, 2007). Lurie (1981) indicates that European clothing over the past few centuries has been used to emphasize women's passivity or sexuality where even power dress is a pale and slightly infantilized version of men's dress. In this way, fashion has tended to offer quite fixed types of roles to women, as sexy, feminine, power-dressing, etc.

Clothing can regulate and control people in a much more overt way. Uniforms suppress difference, create collective identities or foreground the 
role over person. In some Western media representations, Islamic women's clothing is seen in this very manner (Tarlo, 2010). But clothing can be used for resistance (Lurie, 1981). One landmark study was Hebdige's (1979) classic Subculture: The Meaning of Style, which looked at clothing in Britain as a means of working-class resistance. Items of clothing usually associated with formality, refinement and status could be re-used, parodied and combined with other kinds of clothing. Such statements allowed disaffected youth to show rejection of the values of the establishment.

Another landmark text was Gilroy's description of hip hop culture (see Gilroy, 1991). Hip hop began through a sense of disaffection, a counterculture, a rejection and play on dominant representations of black people in a society where they were often marginalized and excluded. But this fashion became something that traps young black people into reproducing a set of associations, essentializing them - even if they may see this as an act of challenge (Gilroy, 1997).

These points are useful in the context of the abaya in the UAE. The abaya can be presented officially as a marker of local or national and religious identity. It can be presented as a kind of resistance to Western type immodest and commercialized fashions. Yet these can be thought of in a process of different levels of essentialization (Yaqin, 2007).

One highly influential idea in the critical study of fashion is that of 'taste'. Bourdieu (1984) provides a sociological account of taste as something largely defined by the ability of the middle classes to place their own preferences as superior and to maintain their distance from other social classes. Good taste in clothing, music and art is presented as an indication of intellect, a more sophisticated and educated character, etc. Taste here is not about qualities inherent in objects, nor can it be related to actual individual matters. Rather, it is socially conditioned and is inscribed into all parts of culture such as the education system. This idea has been taken up to look at the way that fashion choices, particularly in the working classes in Europe, are seen as an indication not only of bad taste, but also, therefore, an indication of a flawed moral character, or simply as proof of their crudeness and low status (Lockyer, 2010).

Scholars point to the way that this idea of taste developed in 19th-century Europe and America (Miller, 2011). Yet, much less attention has been give to the way in which such ideas have been taken on and transformed in other cultures. In the interviews carried out for this article, it was clear that taste is a key marker for the women in regard to forms and features of the abaya, yet this sits next to traditional notions of modesty, how appearance reflects on the family, what is appropriate for a Muslim woman, and so on.

The abaya has been one aspect of the very successful nation building in the UAE where it has been important to create unity across the different tribaloriented formerly independent Emirates. Scholarly work has taken an interest in the use of clothing in the construction of national or ethnic identities. Studies 
show how things like Celtic fashions were not really known until the Victorian period (McCoy, 1995) and the idea of the Scotsman with kilt and bagpipes was an invention of the 19th century in the wave of European Romanticism (Brown, 2012). Maynard (1994) reveals how the idea of traditional male bush clothing in Australia is a myth, a construction, that she traces to a nostalgic idea of male prowess and practical know-how.

Tsul (2013: 580) has shown how such constructed ideas of national character and fashion play a role in the marketing of clothing. Chinese fashion designers are able to gain recognition in the global fashion industry by feeding back Western notions of what China means, through the form of reformulated notions of Zen, through pale and neutral colours, natural fabrics, flowing shapes, or other connoters of peacefulness, calm and harmony.

\section{CLOTHING AND ISLAM}

In her book Visibly Muslim, Tarlo (2010) emphasizes that both within Western societies and across the world there are huge and continually changing differences across Muslim populations as to what is considered the way for women to dress. This depends on many things such as family, culture and context. Women's dress, she points out, is not well defined in the Qur'an, leaving it open to many interpretations.

Through ethnographic work and interviews with people working in retail, Tarlo discusses the great variety of dress available for Muslim women, how the wish to cover up to different degrees can be combined with a range of more contemporary looks, more modern fabrics, or with wider fashion styles. She looks at a small part of the huge online industry that exists through retailers such as The Hijab Shop Online, which sells more colourful hijabs and sports clothing, and Silk Route Hijabs, which addresses a massive market in younger women who want to cover but who want a range of more modern fabrics such as cotton, canvas, Gore-tex, jersey fabric, terricotton, etc., and more subtle and muted colours such as beige. While there appears to have been a renewed interest in covering up by young Muslim women, this is done in a way that is linked to a sense of style informed by living in Western cultures. She shows how the young women have a complex and diverse range of reasons for wanting to cover up, again relating to family, culture and context.

Authors have pointed to similar complexities across different Muslim societies. Moore (2007) showed that in parts of Yemen there have been constant shifts in the way that Muslim women have dressed, with waves of covering and not covering up, but also with constant shifts in styles, cuts and lengths. More recently, there has been a shift to different kinds of dress, particularly the more modern and feminine abaya. Osella and Osella (2007: 341) suggest that, in the case of Muslim women in India, covering up may still be done, but processes of modernization, education and literacy have increased the level of reflexivity and sense of fashion and taste. 
Abaza (2008: 282) argues that, over recent decades in Egypt, Islamic clothing has 'transformed from being an austere marker of resistance to Westernization and upper-class pretensions, to a new form of "embourgeoisement" with the aspirations for social inclusion that this entails'. She gives examples of stores for women that provide different kinds of abaya-type clothing that can match with jeans, scarves and other accessories (p. 289). She says that, along with the influence of global fashion, there is a new kind of Islamic chic.

Yaqin (2007) provides a particularly interesting discussion of an Islamic version of the Barbie doll. The doll is called Razanne, wears a black hijab, is made in the US and sold globally. Yaqin explains that the Razanne doll can, on the one hand, be seen in the context of the US where some Muslim people seek self-representation. But, on the other hand, she asks what this means practically, given that historically 'Islam has been highly differentiated according to the cultural codes of different regions' (p. 185).

Yaqin argues that Razanne is spreading a globalizing image of young Muslim girls, reproducing a stereotype and participating in the 'homogenization of a transnational Islamic identity' (p. 174). This process can collude with the wider society in creating a kind of stereotype, and at the same time serves to construct another stereotype of Western societies. These ideas and representations can then feed into wider international representations regarding notions of what it is that becomes essentialized as 'Western' that should be opposed.

\section{GLOBALIZATION, VISUAL COMMUNICATION AND CULTURE}

In a recent special edition of this journal, Aiello and Pauwels (2014) argued that it is a mistake to assume that neo-liberalism and global capitalism seek to erase difference or to foster homogeneity. Rather, the process is one of exploiting certain kinds of identities and aspects of identities, such as the local, the ethnic or the national (p. 278). They argue that the study of globalization and culture must shift from the media as a site of investigation to the site of the visual. All communication involves the coding of the world and attempts to convey motivated ideas, values and identities. They argue that the visual is particularly important in global communication since it can claim authenticity and resemblance, rather than being simply opinion, and that it is free of language barriers, even where its actual use or purpose may not be clear.

Aiello and Pauwels (2014: 277) argue that globalization research has made little reference to cultural specifics, social inequalities and political and identity struggles. Flows of semiotic material and visual resources across societies, regionally and internationally, take varying and specific ideological forms. The flow and use of the visual plays a part as individuals and different kinds of ideological, class or ethnic groups seek to carry out different kinds 
of definitions for a range of complex purposes. A nation may define a kind of traditional clothing that foregrounds the requirements of present dominant ideologies. What is presented as representative of an ethnic, religious or ideological identity may be transformed in relation to global, or other regional influences.

Identity is performed and managed through the deployment of visual resources to meet specific discursive aims. In regard to the abaya, we must understand its place in a society where it is important to consolidate a distinctive national identity, where young women live as a minority in a complex international population, connected to a wider flow of visual representations about fashion and taste, and often highly motivated media representations of the nature of Islam, where they are bound by a Foucauldian gaze, both of tradition and of modern taste.

\section{A MULTIMODAL APPROACH TO CLOTHING}

Social semiotics is interested in the way that communicators use semiotic resources to achieve particular goals and also to communicate specific ideas, attitudes, values and identities. It explores both the resources available to communicators - in other words, the repertoire of sign/meaning potentials upon which they can draw in order to communicate - and also how these are used in specific cases, in particular combinations, to communicate particular meanings (Van Leeuwen, 2005). The aim is to document the choices that are realized in various contexts and to model these into an inventory of meaning potentials. This approach has been successfully applied to a wide range of semiotic forms under the label of multimodal analysis (Bezemer and Kress, 2010).

Of importance is the idea that all forms of semiotic resources are shaped through how they have developed across historical uses in social contexts to achieve specific communicative aims. As Bezemer and Kress argue, the meanings of these resources will carry these motivations and they will be formed by the social and political environment of the time.

In what follows, supported by open-ended interviews about clothing with 50 female university students in the UAE, I explore the features and forms of the abaya. I use some of the categories developed by Barthes (1983) to look at the meaning potentials in clothing in regard to fabrics, form, textures, colours and designs. I draw on Lurie's (1981) observations of fashion as a kind of language and also on Djonov and Van Leeuwen's (2011) work on texture and Abousnnouga and Machin's (2013) work on the materiality of monuments.

Finally, like Abousnnouga and Machin (2013), the idea of multimodal discourse is important in this analysis. In a Foucauldian (1975) sense, clothing can be seen as the materialization of discourse. Discourses here are a kind of 'script' (Van Leeuwen, 2009) that point to kinds of ideas, values, social relations, ways of doing things and kinds of identities. It is in such scripts that boundaries or possibilities for women are defined. These discourses are materialized in clothing in choices of features and forms. 


\section{SOCIAL SEMIOTICS AND THE ABAYA}

I now present an inventory of meaning potentials that allow me to begin to explore the different ways in which the abaya is changing. The meaning of the garment is created by the way these potentials are realized in combination, which will include things like postures, gestures and settings. But it is necessary to present them in this isolated form for the purposes of description (Van Leeuwen, 2005). For each meaning potential, I first describe the affordances and then apply these to the abaya.

\section{Weight of fabric heavy/light}

Fabrics can be thick, thin, or completely sheer. This can be functionally linked to seasons. But heavier fabrics suggest substance, durability and functionality. They can also give the impression of bulk and can signify 'protective'. When the wearer moves, the fabric tends to remain stable. For Barthes (1983) the heavy/light connotations link to immobility/mobility, or entombment versus sublimity. Barthes suggests that it is a garment's weight that makes it a wing or a shroud, seduction or authority. He notes that ceremonial garments (above all charismatic garments) are generally heavy, where authority is a theme of immobility. Garments that celebrate birth are light and airy, in contrast to those that mourn death, which will be heavy (p. 126). Finer and sheer fabrics suggest lightness and elegance. It would not appear appropriate in a European church wedding for a bride to wear heavy, protective fabrics, for example.

Very light, sheer fabrics are partly transparent and can therefore suggest openness rather than closedness. For a university graduation in Oxford, doctoral candidates would tend to wear a heavier velvet type of robe. The lightness and flow of a sheer fabric would not communicate the appropriate degree of substantiality to the tradition of knowledge.

Lurie (1981: 61), discussing shifting forms of women's clothing, notes that in the 18th century, with the rise of Romanticism, there was a shift to women wearing much lighter, wispy clothing. She relates this to a shift in prescribed feminine identities to emphasize a sense of spontaneity and childlike energy. Lurie notes a shift to the use of thicker cottons and tweeds in the 1970s as women playfully took on more boyish types of fashion.

In the case of the abaya, fabrics must to some extent be lighter due to the heat and need for ventilation - a priority mentioned by many interviewees. But the women also pointed to the way that more conservative clothes tend to look heavier. They made reference to the heavier looking clothing worn by older women. More contemporary, and what they described as more tasteful abayas appear more lightweight and are thought of as more elegant (see Figure 3).

The shayla itself can be worn more as a delicate silk scarf than as a covering. Former head coverings were made of heavier fabrics and would 'hang as a sort of tent over the shoulders' as one interviewee put it. For the young women, these lighter fabrics like silk and chiffon can also connote Paris fashion. The 


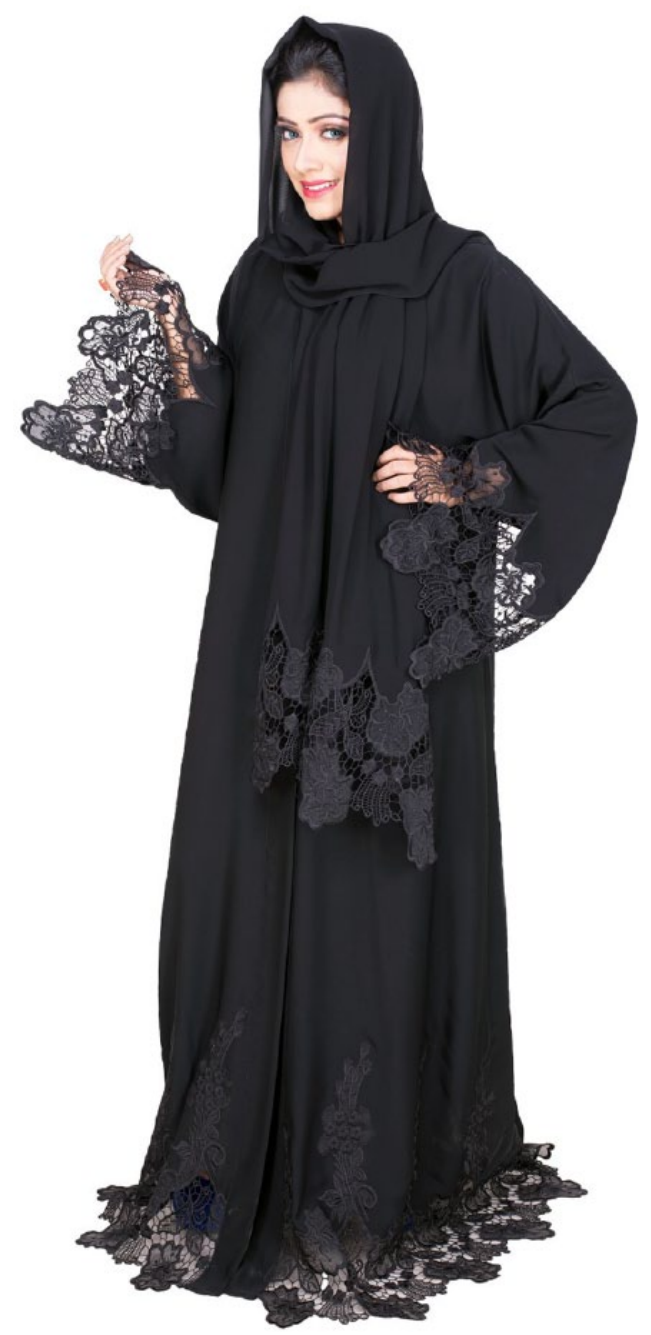

Figure 3. Abaya with lace sleeves.

https://mahlaat.com/index.php/abaya/product-3.html

open abaya (Figure 4) would be of a very lightweight material and tend to flow when walking. Such designs are likely to foster different kinds of movements.

We can see, therefore, a shift away from the abaya as being able to connote covering up in a way that is stifling and authoritative to airiness and movement and to where it can at the same time suggest openness and style rather than functionality, a shift away from a sense of the weight of authority to a sense of airiness and, as Barthes would put it, life. This is notable at a time when women in the UAE are now being encouraged to go out into the public domain, to take university degrees and find professional employment. Yet, as they all point out, this has to be balanced with the need to communicate modesty and tradition in the right social circumstances. 


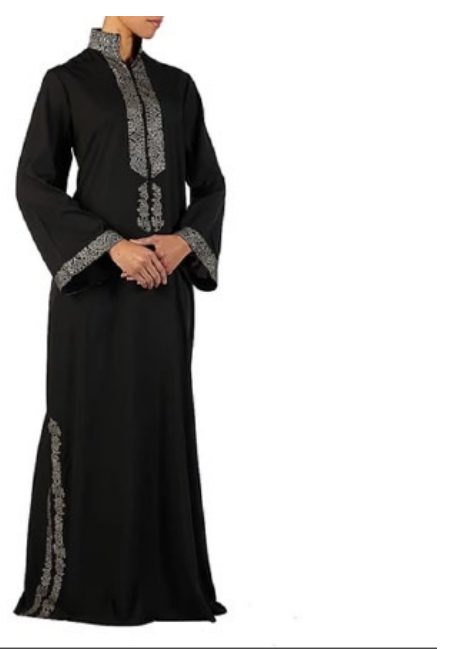

Figure 4. More fitted abaya with cone sleeves. http://www.craftsvilla.com/shop/Amara\%20Black\%20Crepe\%20Abaya\%20With\%20Bell\%20 Shaped\%20Sleeves/4540727

Importantly for the young women, such choices would be made depending upon the social occasion. For work settings, they would wear a more traditional abaya and shayla, describing the clothing as permitting a particular kind of more professional, formal role to be performed. In social settings with friends, this would be different. It was clear that here, in Barthes' sense, the young women had a sense of the connection between such basic garment features and the expression of ideas and of behaviour - in other words, the way that the body materializes discourses or scripts. And what is important here is that the professional remains more bound by the relation to tradition, modesty and connection to the family - something promoted by the government, where women's work is part of looking out for society.

\section{Texture of fabric}

Fabrics can be harsher and grainy in feel, such as rough wool, or highly textured linen, or they can be smooth, shiny and also delicate and silky. They can also feel harder to the touch as in tougher canvas, or softer as in pyjama cloth and silk. Grainier fabrics tend to connote the natural, uncomplicated, the organic or harsh. Smooth, more finely grained fabrics suggest a more processed material that can point to fineness and expense, artifice, or the industrial.

For Lurie (1981), rougher kinds of fabrics are more in tune with the landscape and are associated with rural clothing whereas shiny surfaces are associated with wealth and high quality in many cultures. A loose-knit wool sweater will seem more appropriate for adventurous outdoor walks, whereas a sweater worn by a manager may be finely and smoothly knit. In an organic shop it may be necessary for clothing marked as organic to show signs of textures in order to 
signify lack of artifice. However, new fibres can also come to connote nature or the outdoors, such as Gore-Tex, which is marketed as associated with nature, but also used in cities to connote sport, fitness and 'urban survival.'

Grainier fabrics can signify restraint, austerity and discipline whereas shinier, silkier fabrics can suggest luxury, glamour, sensuality. So, for example in the West, religious or military clothing would be less likely to be smooth, silky and luxurious. A high-security prisoner or special forces soldier would not typically wear soft, finely woven cottons, however durable these in fact were.

In abayas there is a huge and increasing range of textures. For the young women, the more traditional look would involve a very slightly rougher looking texture. But more modern abayas will commonly combine different textures. Tarlo (2007) describes how younger women who wanted to cover up disliked the kinds of frumpy fabrics they associated with their grandmothers' generation, often still sold in shops owned and run by men. She noted the increasing demand for fabrics like linen and canvas. The young women I spoke with in the UAE said that they liked abayas that combined softer elegant silks, which they described as more feminine, but also which carried sections of linen or lighter cottons.

It is common to see abayas with more shiny appearances, often designed as black-on-black patterns, so that there are shinier and silkier patterns in the main fabric. But some of the young women pointed out that textures too had to be appropriate for social contexts, that delicate fabrics would not communicate the right degree of formality.

In their introduction to the special edition on globalization in Visual Communication, Aiello and Pauwels (2014) point to the way that texture may be one important, yet under-investigated, meaning that has been transmitted in the flow of global culture. What is clear in the case of the abaya is that these associations of textures that connote the natural, the flowing, etc. are being used and combined to point to new kinds of associations. Tarlo (2010) highlights the way in which the clothing industry for Muslim women is subtly changing, and differently across regions, yet it is the monolithic idea found in the Razanne doll that tends to persist, or grow, as the essentialized representation. For young women in the UAE, it may be possible to remain modest, to cover up, yet do this with a subtle yet locally transformed sense of the meanings of fabrics. The young women I spoke to said that they perceived the influence of Paris chic and also of Japanese-influenced looks in both textures and cut.

\section{Suppleness - stiff}

Related to texture is the extent to which a fabric holds its form. Is it starched and rigid, or does it move and is it flowing? For Barthes (1983: 127), this suggested meanings related to conformity, subjugation and restraint, versus freedom and the emotional. Some institutions such as the military and schools insist on clothing that is rigid, displaying sharp angular creases. It would not 
be appropriate for soldiers to parade down a street wearing soft, flowing fabrics. Like their postures and movements, they must appear regulated, controlled and precise. Lurie (1981: 61) notes that, in 18th-century Europe, clothing for the upper class was very stiff as there was an emphasis on formality, later giving way to softer fabrics with the rise of Romanticism and spontaneity, and the emphasis on the spirit.

In the case of the abaya, for the young women, there was a sense that the more traditional clothing would have a certain stiffness, perhaps not by being starched and creased, but that more modern clothing should move with the body, 'should have movement', as one young woman suggested. As with weight, there is a sense that the body is freer rather than restricted, or contained. And what is important here is that this may not simply be a matter of these young women finding that their need for 'movement' is now realized through the availability of more mobile fabrics but that they have taken on this meaning through the semiotic meaning potential of the clothing. And, we might suggest, this points to the wider discourse, or script, of which it is a part.

Part of the nature of the global flow of representations is the way in which consumer objects and things become loaded with meanings: a car with adventure, a pair of jeans with urban chic, a beer with freedom. So too, fabrics can become carriers of meanings such as freedom or confidence. The global signification of discourses, identities, ideas and values takes on a different form while at the same time these significations are reformulated.

In fact, some of the girls I interviewed said that the abaya gave them confidence in more formal social settings such as at university and at work. But it was important that these also signalled a modern and stylish look, as one woman said, so that you do not look stifled - or semiotically, that they avoid the immobility suggested by a more starched and heavy garment. In this sense, they can embody both discourses of the Muslim woman playing her part in nation building and those of taste and elegance.

\section{Tight - loose}

This is a more difficult category given that, across fashion history, tightness and looseness have combined in different ways and degrees even on the same garment and through different shapes. Ultimately, semiotically, this must be considered within a range of qualities that are all interconnected. And tight and loose can be of different orders. A garment can be loose in a way that appears baggy, rumpled and formless. Or it can be loose in a way that is designed and tailored to suggest flow and kinds of shape or movement. Barthes (1983) makes three distinctions between skin-tight and clinging, to tight where it is drawn in and contoured, to free flowing. The abaya in Figure 4 is clearly more contoured than we find in Figure 1.

Tight clothing can reveal the shape of the body, but can also appear highly restrictive. But tightness and looseness can also be tailored to add shape to the body. Barthes (1983) pointed to the way such features could not be dealt with 
as a simple opposition. A sleeve can take a cone or ball type shape emphasizing width or slimness at different parts of the body and each must be dealt with in its own case. So description would address qualities such as straight, rounded, pointed, cubic, squared, spherical, tapered. All could be opposed to the others. But, he suggests, straight versus curved are the fundamental categories. So straight can be squared, tapered, pointed, bevelled. Curved can be round, flared, oval. Straight can be cubic, whereas curved can create a ball or bell.

Importantly, for Barthes (1983), these can relate to how the garment adheres to the body and the way it moves away from the body and the space around the garment. The more traditional look abaya in Figure 1 does not respond in any way to the form of the body. Shoulders are not distinct, the waist is not apparent. In the context of contemporary abayas, we can find a range from very loose forms, which tend not to point to individual features of the body, to those that are more tailored to create tightness in different places. This can be around the waist and shoulders, which emphasizes the figure. This may be combined with looser flowing, lighter shaylas or other sections to also bring a sense of modesty and flow. Sleeves can be cone shaped, as in Figure 4, so that they are tighter on the upper arms and then open widely creating much movement in the fabric when the arm is moved. The young women I spoke to described such garments through adjectives such as 'elegant' and 'chic', with the combination of fitted lines to emphasize bodily form with a combination of the more flowing sleeves. They were clear this would not be suitable for more public settings although different interviewees had very different perceptions of this. And, importantly, they were aware that such form changed with fashion. A year back, they said, the waist was slightly drawn in as belts were worn, but these had gone out of fashion.

\section{Continuity and open - closed}

Clothing can be comprised of one unit or many. A babygro comprises one piece of clothing. Some raincoats combine the hood into the design of the coat. Garments can create continuity and discontinuity with the body - for example, a jacket can be shorter and end well above the waist or it can extend down to around the knees. The continuity or discontinuity can be either emphasized or played down. There can also be different degrees of the body becoming enveloped so that its form is de-emphasized. The legs can be differentiated in trousers to different degrees by looseness and tightness, or undifferentiated in a longer skirt.

Osella and Osella (2007) and Moore (2007) point to the ways in which covering up in different Muslim societies has taken many forms, which has included clearly distinct garments where a skirt, or trousers, jacket and head covering are distinct units. These, to different degrees, might allow different sections of the bodily shape to be seen - in India with the waist at one time being exposed and loose trousers being worn. There have also been shifts in the positioning of sections, for example, making the waist higher or lower, and 
changing the leg-torso proportions. These authors point to how this whole process has become more connected to international fashion.

We can think about this in the context of Lurie's (1981) observations on how women's fashion shifted in relation to wider social attitudes to women, was more forceful, as more wispy and dreamy or as more sexually alluring where the waist, chest and length of the legs were emphasized.

The abaya itself is less integrated than the older style head abaya (Figure 2), particularly where the head, face and form of the neck can be emphasized with the shayla. But it also marks a shift away from some of the older forms of covering seen in photographs of UAE women from the 1960s, with a longer head covering, skirt and longer jacket. To some extent, the abaya can signify a shift to continuity where there are no clear units. This appears to be related to the newer wave of womenswear covering in different societies (Tarlo, 2010). In one sense, it signifies difference from the more differentiated Western type of clothing. But the abaya also allows covering to be signified in a way that permits other kinds of semiotic features. In a sense, the singular form allows a palette that signifies difference, Islamic fashion, yet therefore allows combinations more easily. One young woman said that the advantage of the abaya is that it gives a flexibility to combine different kinds of looks for different settings, yet always shows a sense of modesty.

One important feature of continuity/discontinuity is the difference between open and closed. A sweater is different from a cardigan in that it cannot be opened. It contains the body in a way that the cardigan does not. This has important semiotic meaning. Why would it not be right for a policeman to wear a jacket open? A doctor can do so with his white coat, but a nurse may not be able to do so (although this is changing as they become professionalized). Open-closed clearly points to a barrier, to formality (buttoned-up) and order. Buttoned-up can suggest a barrier and privacy. But there can be different types and levels of openings. Clothing can be buttoned up or left open to suggest relaxation, at ease and informality. This also suggests the ability to express the choice or power to do so. The policeman does not have power in himself, as does the doctor, but only through his uniform. A child may have to get permission to open buttons on a uniform. A person caught for bank robbery may be confused if the arresting officer had his shirt open to the navel.

While they were all formerly closed, many abayas now have buttons down the middle. This can allow wearers to reveal the clothing they have on beneath to a more or lesser extent, as they choose. Here, thought will also usually be given to colour coordination between the abaya and other clothing. Buttons can be partially undone to reveal a particular top, or jewellery. Or it can be worn fully open. This can be quickly changed for various social contexts.

An abaya can also be shorter so that trousers, shoes (see Figure 5) or other garments can be seen. In all these cases, the austerity or moderation indicated by the closedness of the traditional abaya are lessened to different degrees. Yet the main garment remains faithful to the locality and to religious 


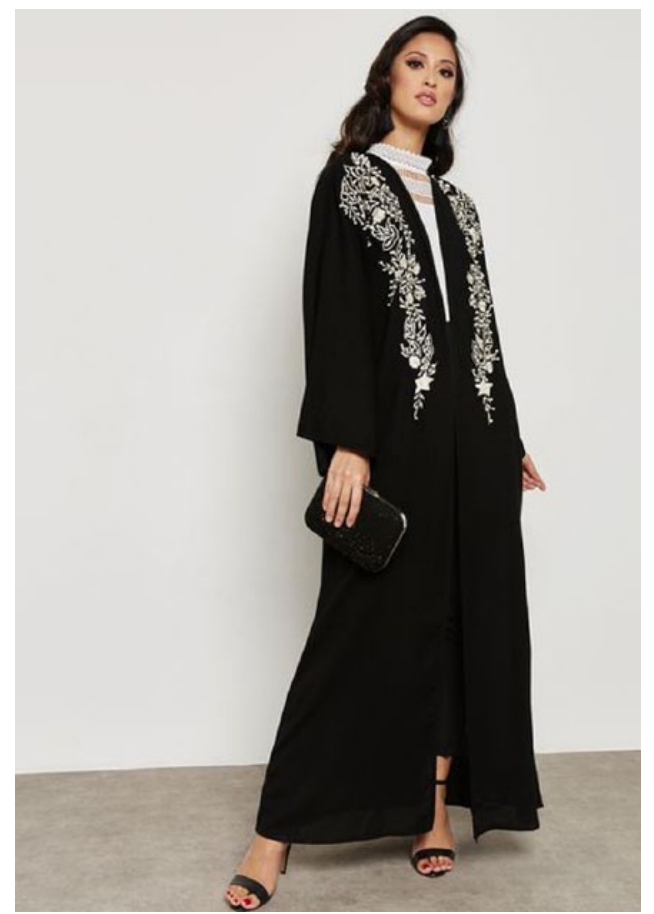

Figure 5. Open abaya.

https://pa.namshicdn.com/product/54/6203/vl/I-web-desktop-product.jpg Haya's Closet

modesty. One girl stressed that for a trip to the mall she would not wear an unbuttoned abaya, but she would certainly wear one that was shorter so that her (designer) shoes could be seen, which would match other accessories.

\section{Colour palette}

Kress and Van Leeuwen (2002) provide one way to think about the meaning potentials of colours that sit alongside some of the observations of Gage (1999), who points specifically to the use of colour on clothing as a marker of social status, wealth, or clearly defined symbolic values. Most important from a social semiotic perspective is that while the symbolism of colours may have historical and cultural interest, the social dimension refers to the kind of social participation implied by these colours. So, if mourning is black rather than orange and red, what kinds of ideas, attitudes and identities does this involve, in the same way that a birth or wedding require lighter, rather than heavier fabrics?

From speaking with the young women, a number of colour qualities appear important. More traditional abayas tend to have very limited colour palettes, using just black. Black is spoken of in terms of moderation and not attracting attention to oneself. More contemporary abayas use more colour, although these can be considered crude, garish and tasteless by some women. Some colour hues are favoured, such as greys and blues. Gold is also important for its 


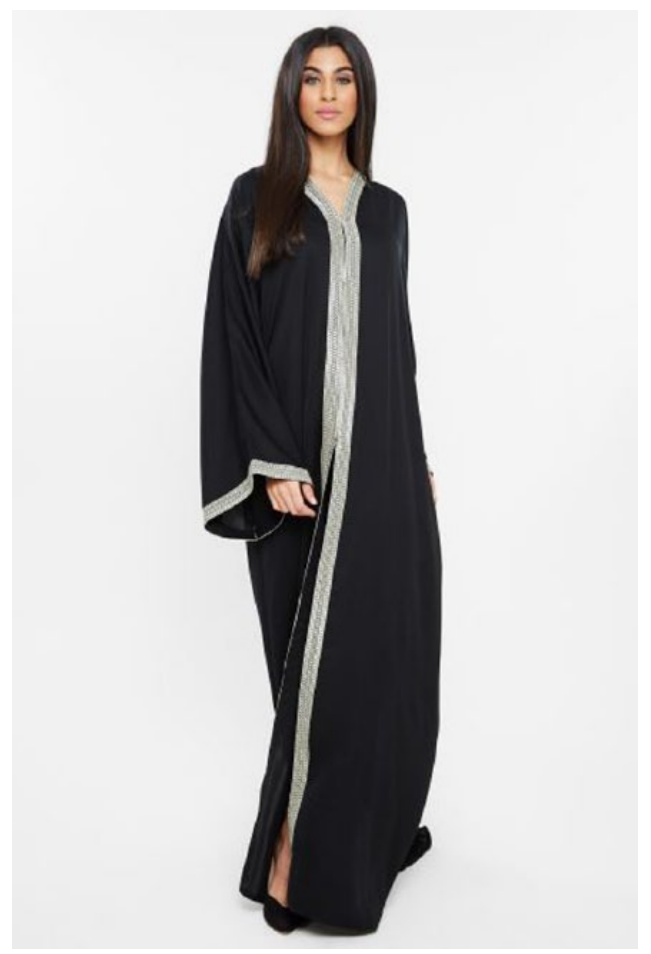

Figure 6. Abaya with muted colours.

https://uae.souq.com/ae-en/nukhbaa-black-casual-abaya-for-women-I | 878037/i/

connotations of lavishness, wealth and status. But, for many young women, the more tasteful contemporary abaya carries a limited amount of more muted and subtle colours as seen in Figure 6. As in contemporary fashion design, it is common to find more muted colour with one predominant key colour.

Even moderately coloured abayas (see Figure 7), given that this can mean liveliness, may not be considered suitable by some young women who interpret this as attracting attention. A shorter abaya with cone sleeves and slightly drawn-in waist, which reveals high-heeled designer shoes and which may match a handbag, is appropriate, whereas brightness is not.

Colour coordination is also something that has become very important, according to the interviewees, and seems to be an indication of class - the young women are culturally oriented not to be critical of others, so this was never stated openly. This coordination is seen clearly in online abaya stores where linking is found across abayas and shaylas. Women will also coordinate with accessories, such as shoes, handbags, and so on.

\section{CONCLUSION}

What most interests me in the analysis carried out in this article is the materialization of discourse - in the way that clothing allows us to inhabit dis- 


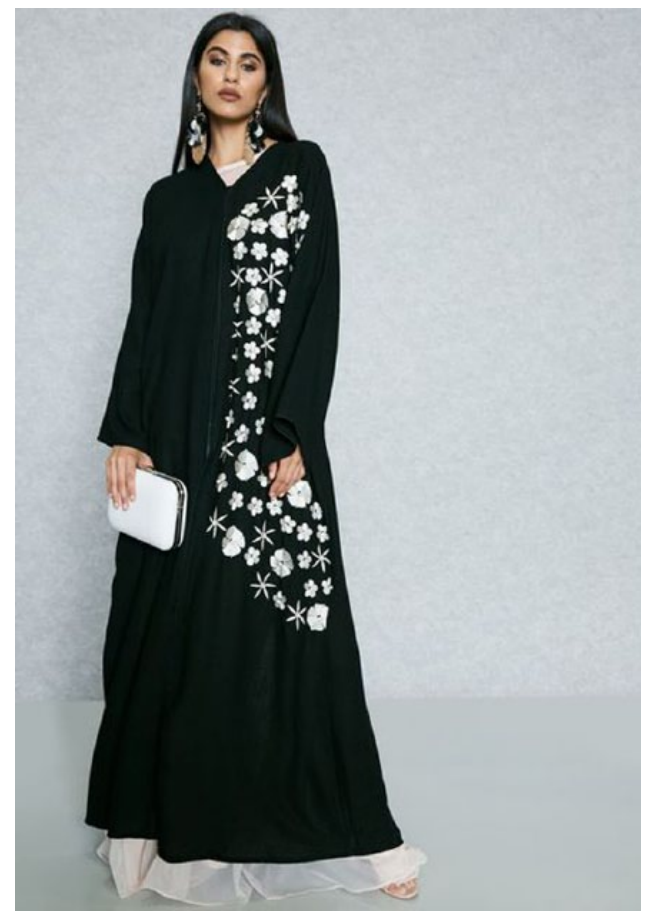

Figure 7. Abaya with floral design.

https://pa.namshicdn.com/product/54/5062/v5/I-web-desktop-product.jpg

https://en-ae.namshi.com/buy-hayas-closet-one-side-embroidered-pearl-abaya-for-womenabayas-260545.html

Haya's closet

courses that become infused into our bodies. As Barthes (2005) points out, it can be hard to track the ideological origins, or nature, of all the semiotic meanings in clothing. But it is possible to start to show how features and forms of clothing can carry ideas, values and attitudes that perform a role in defining boundaries and possibilities for identities - which can be inhabited by the wearer. We have seen how the abaya can allow the body to realize a discourse of a more professional and confident identity in a way that can still remain faithful to a more traditional, family-oriented, supportive female role. In public spaces, the abaya can be modified, carry connotations of soft femininity, or chic Paris fashion. And it can indicate taste and social class. These semiotic choices are regulated by different forces and involve personal uses in contexts, as indicated by the scholarly literature on fashion. But what we have seen in this analysis points to the flow of visual and textural semiotic resources around the world, which can be used, adapted and transformed for identity work. In this sense, they are deeply political. What we have begun to see are the ways that fashion and its semiotic components cannot be understood independently of ideology and the values and ideas that it tries to enforce. 


\section{F U N D I N G}

This research received no specific grant from any funding agency in the public, commercial, or not-for-profit sectors and there is no conflict of interest.

\section{REFERENCES}

Abaza, M. (2008) Shifting landscapes of fashion in contemporary Egypt. Fashion Theory 11(2-3): 281-298.

Abousnnouga, G. and Machin, D. (2013) The Language of War Monuments. London: Continuum.

Aiello, G. and Pauwels, L. (2014) Special Issue: Difference and Globalization. Visual Communication 13(3): 275-285.

Al-Muktar, R. (2011) Saudi women are expressing it through an Abaya Revolution. Sayidaty: 34-37.

Ambah, F.S. (2007) For cloaked women, color is the new black. Washington Post, 28 May: 9.

Barthes, R. (1983) The Language of Fashion. London: Bloomsbury.

Barthes, R. (2005) The Language of Fashion. Oxford: Berg.

Bezemer, J. and Kress, G. (2010) Changing text: A social semiotic analysis of textbooks. Designs for Learning 3(1/2): 10-29.

Bourdieu, P. (1984) Distinction: A Social Critique of the Judgment of Taste. Cambridge, MA: Harvard University Press.

Bristol-Rhys, J. (2010) Emirati Women. London: Hurst.

Brown, I. (2012) Tarten, Tartenry and Hybridity. In: Brown, I. (ed.) From Tartan to Tartenry: Scottish Culture History and Myth. Oxford: Oxford University Press.

Carvalho Pinto, V. (2012) Nation-Building: State and the Genderframing of Women's Rights in the UAE. Reading: Ithaca Press.

Crane, D. (2000) Fashion and Its Social Agendas. Chicago: Chicago University Press.

Crane, D. and Bovone, L. (2006) Approaches to material culture: The sociology of fashion and clothing. Poetics 34: 319-333.

Djonov, E. and Van Leeuwen, T. (2011) The semiotics of texture: From tactile to visual. Visual Communication 10(4): 541-564.

Foucault, M. (1975) Discipline and Punish: The Birth of the Prison. New York: Vintage Books.

Gage, J. (1999) Colour and Meaning. Los Angeles: University of California Press.

Gilroy, P. (1991) 'There Ain't No Black in the Union Jack': The Cultural Politics of Race and Nation. London: Routledge.

Gilroy, P. (1997) Diaspora and the detours of identity. In: Woodward, K. (ed.) Identity and Difference. London: Sage, 299-343.

Hebdige, D. (1979) Subculture, the Meaning of Style. London: Methuen.

Kress, G. and Selander, S. (2012) Multimodal design, learning and cultures of recognition. Internet and Higher Education 15(4): 265-268. 
Kress, G. and Van Leeuwen, T. (2002) Colour as a semiotic mode: Notes for a grammar of colour. Visual Communication 1: 343-368.

Lockyer, S. (2010) Dynamics of social class contempt in contemporary British television comedy. Social Semiotics 20(2): 12-138.

Lurie, A. (1981) The Language of Clothes. London: Random House.

Maynard, M. (1994) Fashioned from Penury: Dress as Cultural Practice in Colonial Australia. Cambridge: Cambridge University Press.

McCoy, E. (1995) Celtic Myth and Magick: Harness the Power of the Gods and Goddesses. St Paul, MN: Llewellyn Worldwide.

Miller, J. (2011) Fashion and Music. London: Berg.

Moore, A. (2007) Fashionable Muslims, notions of self, religion and society in San'a. Fashion Theory 11(2/3): 319-346.

Osella, C. and Osella, F. (2007) Muslim style in South India. Fashion Theory 11(2/3): 233-252.

Tarlo, E. (2007) Hijab in London: Metamorphosis, resonance and effects. Journal of Material Culture 12(2): 131-156.

Tarlo, E. (2010) Visibly Muslim. Oxford: Berg.

Tsul, C. (2013) From symbol to spirit: Changing conceptions of national identity in Chinese Fashion. Fashion Theory 17(5): 579-604.

Twigg, J. (2007) Clothing, age and the body: A critical review. Aging and Society 27(2): 288.

Van Leeuwen, T. (2005) Introducing Social Semiotics. London: Routledge.

Van Leeuwen, T. (2009) Discourse as Practice. London: Routledge.

Wilson, E. (1985) Adorned in Dreams: Fashion and Modernity. Los Angeles: University of California Press.

Yaqin, A. (2007) Islamic Barbie: The politics of gender and performativity. Fashion Theory 11(2/3): 173-188.

\section{BIOGRAPHICAL NOTE}

GWEN BOUVIER is a Lecturer at Maynooth University. Her main areas of research interest are social media, civic discourse and news representation. Dr Bouvier's publications have focused on multimodal and critical discourse analysis, social media, fashion as discourse and the visual representation of crises in news. She is a Review Editor for the Journal of Multicultural Discourses and the Editorial Assistant for Social Semiotics. Her latest publications include an edited volume: Discourse and Social Media (Routledge, 2016), 'Discourse in clothing: The social semiotics of modesty and chic in hijab fashion', Gender and Language 2016, 10(3): 364-385; and 'How journalists source trending social media feeds: A critical discourse perspective on Twitter, Journalism Studies (2018): http://www.tandfonline.com/doi/abs/10. 1080/1461670X.2017.1365618

Address: Iontas Building, Maynooth University, Maynooth, Co. Kildare, Ireland. [email: gwen.bouvier@mu.ie] 